\title{
Participación indígena en Qollasuyu: la elección de constituyentes en Chile
}

\section{Indigenous participation in Qollasuyu: the election of constituents in Chile}

Fecha recepción: 7 de junio de 2021 / fecha aceptación: 1 julio de 2021

\author{
Andrea Ibacache-Corante ${ }^{1}$
}

\begin{abstract}
Resumen
El presente texto busca entregar aproximaciones sociológicas para analizar las cifras de participación en las elecciones de constituyentes indígenas de las siguientes comunidades: aymaras, changos, collas, diaguitas, atacameños o lickanantay y quechuas, en las elecciones de representantes para la Convención Constitucional en Chile. Para ello se analizan las cifras entregadas por el Servicio Electoral de Chile, SERVEL, donde se develan a los pueblos de mayor y menor participación, contribuyendo además con argumentos históricos que permiten justificar sus movimientos electorales. Se utiliza la distinción geográfica de Qollasuyu como históricamente se denominaba a uno de los cuatros suyus del Imperio Inca, como gesto cultural, político y reivindicativo.
\end{abstract}

Palabras claves: Qollasuyu, indígenas, Constitución, participación, reconocimiento

1 Dra. (c) en Estudios Americanos, especialidad Estudios Sociales y Políticos, Instituto de Estudios Avanzados, Universidad de Santiago de Chile. Becaria ANID doctorado nacional. Dirección postal: Román Díaz 89, Providencia, Santiago de Chile. Correo electrónico: andrea.ibacache.c@usach.cl_ 


\begin{abstract}
The present text seeks to provide sociological approaches to analyze the participation figures in the elections of indigenous constituents of the following communities: Aymara, Changos, Collas, Diaguitas, Atacameños or Lickanantay and Quechuas; in the elections of representatives for the Constitutional Convention in Chile. For this purpose, the figures provided by the Chilean Electoral Service, SERVEL, are analyzed, where the peoples with the highest and lowest participation are revealed, also contributing with historical arguments that allow justifying their electoral movements. The geographical distinction of Qollasuyu, as one of the four suyus of the Inca Empire was historically called, is used as a cultural, political and vindicating gesture.
\end{abstract}

Keywords: Qollasuyu, indigenous people, Constitution, participation, recognition

\title{
Introducción
}

Por primera vez en Chile la población indígena tiene la posibilidad de participar de elecciones acorde a un padrón electoral específico que delimita su pertenencia étnica. Pero el camino que construye este hecho histórico se remonta hace un par de años y va en sintonía con diversos procesos sociales donde la ciudadanía latinoamericana cuestiona a sus gobernantes y la forma de hacer democracia.

En Latinoamérica, Ecuador y Bolivia son algunos de los países más avanzados en la materia, entregando reconocimiento en sus Constituciones que se expresa en diversas dimensiones (Naciones Unidas, 2021). Esto se relaciona con la cantidad de población que se considera indígena. Es precisamente esta pertenencia étnica la que permite mayores derechos en materias como tierras, política, aspectos sociales, culturales, etc. De esta forma se legitiman temas tan diversos como el acceso a la medicina tradicional, derechos de representación política y autonomía y autodeterminación, entre otros (Fuentes y Sánchez, 2018).

Sin duda hablamos de un proceso histórico en Chile, que permite acercarse a una democracia participativa no solo en relación a una Nueva Constitución, sino a la justificación de la participación activa de indígenas en la institucionalidad pública, Entendemos la participación como un elemento importante en las democracias contemporáneas, expresado de diversas formas que permiten legitimar diversas acciones para la toma de 
decisiones, permitiendo una distribución de poder (Henríquez, 2013). Sin embargo, diversos sectores indígenas no validan el proceso constitucional, al asimilarlo con otras experiencias fallidas como las diversas Consultas Indígenas, lo que podría justificar a quienes no participaron en estas elecciones (Albert, 2019). Los conflictos históricos entre la población indígena y el Estado siguen presentes, donde la falta de diálogos respetuosos, el reconocimiento de las naciones preexistentes y el trato subalternizado y racializado no han permitido acuerdos duraderos; como el caso del abordaje de la población mapuche como disidentes no ayuda para la resolución de conflictos (Figueroa Huencho, 2018). Los Constituyentes Indígenas permiten hablar de una democracia horizontal con mayores expectativas de Plurinacionalidad, donde existe la posibilidad que expongan sus cosmovisiones e ideas de autonomía ante una democracia que desconoce estos conceptos. La existencia de los escaños reservados indígenas permite vigorizar el proceso político reconociendo la discriminación a la que está sujeta la población originaria. Es un momento histórico donde se inicia una aproximación a la materialización de la autodeterminación como ejercicio de la autonomía (Pairican, 2016).

Si analizamos geográficamente la presencia indígena, podemos encontrar cuatro amplios territorios de naciones preexistentes en Chile: Qollasuyu, Wallmapu, Rapa Nui y Patagonia. Para el presente trabajo, haremos la distinción geográfica de Qollasuyu, (Rostworowski, 2019) como uno de los suyos de Tahuantinsuyu, el Imperio Inca; como distinción reivindicativa, política, y como elemento diferenciador acorde a la cosmogonía andina presente en lo que hoy se conoce como territorio chileno. A modo de georreferencia, hablamos de los pueblos indígenas que hoy son parte de las regiones de Arica y Parinacota, Tarapacá, Antofagasta, Atacama, Coquimbo, Valparaíso y Metropolitana. Sin embargo, la presencia de aymaras, changos, collas, diaguitas, atacameños o lickanantay y quechuas sobrepasa a las regiones mencionadas.

Como contexto, se desglosan ciertas temáticas sociológicas pertinentes para más tarde ser contrastadas con cifras de participación en las elecciones que eligieron a los Constituyentes Indígenas. En el capítulo dos se problematizará sobre la participación indígena en América Latina, destacando su reconocimiento en constituciones y especificando las dimensiones en las cuales se desarrolla, enfatizando a los países que hoy conforman el antiguo Qollasuyu como Perú y Bolivia. En el apartado tres se menciona el caso 
particular de Chile como uno de los países más atrasados en materia de reconocimiento y participación, además de la institucionalización indígena expresada mediante la creación de la Ley Indígena y la Corporación Nacional Indígena, CONADI. En el capítulo cuatro se menciona los recientes hechos políticos en Chile expresados desde el denominado estallido social del 18 de octubre de 2019 y concretados en la redacción de una nueva Constitución. En el apartado cinco se abordan las particularidades de la cosmovisión indígena andina, destacando a la figura del ayllu como unidad política acorde las formas de democracia preexistente y política salvaje. En el capítulo seis se analiza los datos cuantitativos del SERVEL, presentando la metodología de trabajo. Se concluye relatando una síntesis de los temas abordados, proyecciones y posibles interpretaciones de participación.

\section{Participación y Reconocimiento indígena en Latinoamérica}

Ya sea desde los planteamientos de Colonialidad del Poder de Aníbal Quijano (2013) o desde el concepto de indigenismo (Bengoa, 2000), la búsqueda de políticas de superación de la opresión y del racismo permiten manifestar el componente indígena y afrodescendiente presente en América. Para Quijano (2013) la colonialidad como producto de la colonización se consolida mediante un sistema capitalista, globalizado, eurocentrado y hegemónico; donde la raza importa en la distribución del poder y del trabajo. Sin embargo, las consecuencias más evidentes para Latinoamérica nos hablan de violencia, desigualdad, racialización y opresión. Estas asimetrías se producen y reproducen desde la función de la raza, donde saberes ancestrales son desplazados.

Para hablar de planteamientos indígenas, se ha comenzado a hablar con fuerza desde movimientos urbanos que posicionan a las primeras naciones como minorías que no hablan de identidades no reconocidas, reivindicando cosmovisiones lejanas a ideas occidentales de explotación. En estas ideas se basa la idea de indigenismo, que busca articular lo cultural y político, conjugando con elementos de colonialidad del poder de Quijano (2013) con estrategias de sobrevivencia expresadas como resistencia alternativa.

El indigenismo contiene tres elementos a nuestro modo de ver inseparables: la denuncia de la opresión del indio, la búsqueda de políticas de superación de la situación indígena por el camino de su integración al conjunto de la sociedad y la manifestación, 
como consecuencia de lo anterior, del carácter mestizo, indoamericano, del continente. Es un programa de denuncia y autoafirmación. Rescate de lo indígena para afirmar una identidad compleja, propia, autónoma y diferenciada de la cultura occidental (Bengoa, 2000, p. 205).

Al reconocer la especificidad histórico-cultural de los pueblos se pueden generar nuevas formas de participación y organización; sin embargo, pareciera que los Estados ven amenazas donde no las hay en relación a la autodeterminación indígena. Probablemente sea el concepto de soberanía el que genera temor en los Estados ante las demandas indígenas. La soberanía (Soto et al., 2019) es el poder de crear derecho, donde no se somete a ningún otro poder, donde el pueblo tiene la toma de decisiones; o conocida también como la autodeterminación de los pueblos. Es decir, solo el pueblo puede ejercer la soberanía, estando la ocupación, dirección y control vinculante del poder del Estado sujeto a la soberanía del pueblo. Lo complejo del concepto es la idea unitaria del Estado, pero, al visualizar al poder de una forma descentralizada, podría existir cabida para la noción de Estados Plurinacionales (Soto et al., 2019).

Una forma de asegurar la distribución del poder de los Estados se expresa en las Constituciones, en las cuales se puede expresar el reconocimiento de la variedad de culturas que conforman un mismo territorio. En la Declaración de Derechos de los Pueblos Indígenas de la Asamblea General de las Naciones Unidas (2007) se reconoce el derecho a la autodeterminación. El reconocimiento plurinacional se concreta con el reconocimiento de derechos colectivos pensados para la autonomía y participación, lo que en el ejercicio se acompaña de manifestaciones étnicas y culturales (Soto et al., 2019). En las Constituciones de Bolivia y Ecuador, en el primer artículo, se estipula la plurinacionalidad de sus naciones, asegurando un trato intercultural, descentralizado, democrático, independiente; es decir, se consideran otras formas de interpretar el mundo en el marco institucional.

Los derechos colectivos se atribuyen, por normas internacionales y por Constituciones de Estados plurinacionales, a los pueblos indígenas en tanto sujetos colectivos. El fundamento de su reconocimiento está en el derecho a la autodeterminación, expresándose en diversas formas de participación que se aseguran a nivel estatal. En esta línea, se establecen derechos tales como derechos de control sobre los recursos naturales, derechos lingüísticos, espacios de 
representación política especiales, como cuotas o escaños, entre otros. Su ejercicio se realiza a través de individuos representativos, o bien por cualquier sujeto individual que pertenezca a pueblos indígenas. Su finalidad es el reconocimiento de los pueblos indígenas como sujetos políticos preexistentes, anteriores y con dignidad equivalente a la nación construida por el Estado (Soto et al., 2019, p. 59).

Las libertades democráticas se obtienen más allá del voto. Hoy, diversos sectores de la sociedad cuentan con mayores habilidades organizativas que van generando nuevas expectativas que pueden movilizar la adhesión hacia una causa, como sucedió en el Chile mediante el Plebiscito Nacional del 25 de octubre de 2020, donde la ciudadanía aprobó la redacción de una Nueva Constitución (Gobierno de Chile, 2019). Resulta llamativo ver, como se verá en el apartado cinco, si quienes adhieren a otras formas de democracia, como los ayllus, logran conjugar sus propias formas de autogobierno con la institucionalidad pública.

El hecho de que en varias Constituciones latinoamericanas exista un reconocimiento constitucional nos habla del retraso chileno en materia indígena (Naciones Unidas, 2021). Esta presencia constitucional es una apertura importante al diálogo. Países como Nueva Zelanda, Bolivia, Colombia, Perú, Venezuela, México y Ecuador se convierten en casos emblemáticos donde se considera al menos en algún grado el reconocimiento y participación de sus comunidades indígenas, incluso muchas veces son catalogadas como naciones ancestrales (Fuentes y Sánchez, 2018). La diversidad debe ser representada para un correcto debate democrático, considerando las diversas instancias que se retroalimentan y entrecruzan y que logran promover la presencia indígena en los países mencionados. En Fuentes y Sánchez (2018, p.2) se refieren a "una acción para contribuir a remediar las desigualdades de poder presentes en los sistemas políticos"; es decir, existiría un equilibrio del poder, de los resultados y decisiones de política pública. Uno de los mecanismos que podría ayudar a enfrentar los dilemas de representación son los asientos reservados que permiten garantizar un porcentaje de decisión para grupos minoritarios o con identidades étnicas como el caso indígena. Sin embargo, la repartición de estos asientos suele reflejar el poder político de las poblaciones indígenas, siendo la población mapuche o Wallmapu quienes cuentan con mayor poder político-social (Fuentes y Sánchez, 2018). Este dato deja entrever ciertos grados de desigualdad o, 
eventualmente, menos asientos reservados para otras poblaciones, usualmente segmentadas como zonas andinas o zonas del sur, encriptando a diversos pueblos con cosmovisiones similares pero dilemas diversos. Otro punto a considerar es la cantidad de población indígena, contabilizada por el Censo y CONADI; donde se encuentran cifras de autoidentificación que pueden ir aumentando con el tiempo. Ya sea como estrategia política o bien por los recientes procesos de etnogénesis, la pertenencia indígena está en ascenso (Centro de Estudios Interculturales e Indígenas CIIR, 2019).

\section{Participación y Reconocimiento indígena en Chile}

La participación indígena también es considerada como la expresión de una minoría. La opinión pública se identifica con diversas dimensiones en disyuntiva, como el género u origen étnico. De esta forma se enriquece el debate democrático (Fuentes y Sánchez, 2018). Los movimientos indígenas son un nuevo actor social que desafía a las instituciones y Políticas Públicas. Estas últimas pueden acoger poderosos instrumentos claves de organización, a pesar del privilegio occidental que entregan los gobiernos incluyendo de forma precaria a las demandas indígenas. Al respecto, la académica mapuche Verónica Figueroa Huencho (2018) propone contar con enfoques dinámicos donde se quiebren lógicas coloniales. Si bien en Chile la participación se materializa con el Convenio OIT 169, la Ley Indígena $\mathrm{N}^{\mathrm{o}} 19.253$ y la Corporación Nacional de Desarrollo Indígena, CONADI, siguen existiendo diferencias o cabos sueltos entre las necesidades de los pueblos indígenas y la mirada estatal, muchas veces sesgada (Fuentes y Sánchez, 2018).

Un instrumento particular que emerge desde el Estado chileno es la creación de la Comisión Verdad Histórica y Nuevo Trato, el cual no solo sintetiza la relación histórica entre indígenas y el Estado, sino también entrega sugerencias para cada pueblo acorde a sus necesidades. En Chile se han presentado tres nociones ante el Congreso Nacional para introducir escaños reservados; sin embargo, se operacionalizan con otros criterios. "Ninguna de estas propuestas ha sido exitosa y ninguna de ellas logró avanzar en el tramite legislativo. No han existido proyectos de ley en esta materia originadas ni desde el Senado ni desde el poder Ejecutivo" (Fuentes y Sánchez, 2018, p. 16). El debate considera tres dimensiones: el derecho a autodeterminarse (reconocido por el derecho internacional y por instrumentos donde 
Chile forma parte), una representación descriptiva para reflejar la diversidad social y al vínculo entre representado y representantes.

Entre otros hitos similares sobre derechos indígenas se destaca: Pacto de Nueva Imperial en 1989, Ley Pascua, Ley Lafkenche, Reforma Agraria de Salvador Allende. Estos intentos de diálogo no solo reconocen la preexistencia y una deuda histórica, sino también sugieren el reconocimiento constitucional (Bengoa, 2000).

\section{Proceso Constituyente}

El 18 de octubre del 2019 se conoce como "estallido social”, un día que dio inicio a una serie de jornadas de protestas y movilización de la ciudadanía para manifestar su malestar con diversas decisiones gubernamentales que no sintonizan con un país de apariencia exitosa desde el extranjero, pero profundamente desigual. Para calmar los ánimos, el 15 de noviembre del mismo año diversos representantes de las fuerzas políticas firman el “Acuerdo por la Paz Social y la Nueva Constitución” (Gobierno de Chile, 2019), donde se acuerda la redacción de una nueva Carta Magna tras constantes cuestionamientos sobre su origen desde la dictadura y las diversas trabas que impiden cambios profundos para aminorar las desigualdades en Chile. En este acuerdo se permite a la ciudadanía elegir entre una Convención Constitucional y una Convención Mixta que permite la participación de políticos que ya son parte de la institucionalidad pública. La crisis en Chile también habla de falta de legitimidad hacia las fuerzas políticas, lo que se manifiesta con la elección ciudadana de la Convención Constitucional. Más tarde, en diciembre del 2020 se promulga la Ley 21.298 que "modifica la Carta Fundamental para reservar Escaños a Representantes de los Pueblos Indígenas en la Convención Constitucional y para resguardar y promover la participación de las personas con discapacidad en la elección de Convencionales Constituyentes" (Ministerio de Desarrollo Social y Familia, 2021). En la disposición cuadragésima tercera se señala:

Podrán ser candidatos o candidatas las personas indígenas que cumplan los requisitos establecidos en el artículo 13 de esta Constitución. Los candidatos deberán acreditar su condición de pertenecientes a algún pueblo, mediante el correspondiente certificado de la calidad de indígena emitido por la Corporación Nacional de Desarrollo Indígena. Para el caso de las candidaturas del pueblo 
Chango, la calidad indígena se acreditará mediante una declaración jurada según lo dispuesto en el inciso décimo de esta disposición, o la solicitud de calidad de indígena presentada ante la Corporación Nacional de Desarrollo Indígena. Cada candidato se inscribirá para representar a un solo pueblo indígena al cual pertenezca, dentro de los pueblos reconocidos por el artículo $1^{\circ}$ de la ley $\mathrm{N}^{\mathrm{o}} 19.253$ (Ministerio de Desarrollo Social y Familia, 2021).

Los candidatos debieron acreditar su domicilio en territorios de los pueblos a los que pertenezcan. En esta ley también se señala los mecanismos para validar la inscripción de las candidaturas, como el patrocinio por parte de comunidades y obtención de firmas. Como también se acordó la paridad de género, cada candidato indígena inscrito debe inscribir una candidatura paritaria alternativa del sexo opuesto, que cumpla con los mismos requisitos del o la candidata que se deba sustituir por razones de paridad. Es decir, los candidatos fueron presentados como duplas que serían resueltas tras la resolución de la paridad (Servicio Electoral de Chile, 2021).

Para que el padrón indígena ejerciera el voto se crearon cédulas electorales diferentes para cada pueblo con los nombres de todos los candidatos o candidatas. Esta cédula también se conoció como la "papeleta verde". El Servicio Electoral de Chile, SERVEL identifica a los electores indígenas mediante el Registro Nacional de Calidades Indígenas, datos administrativos que contengan apellidos indígenas evidentes, postulantes a Beca Indígena, registro especial para la elección de consejeros indígenas de la Corporación Nacional Indígena, CONADI, Registro de Comunidades y Asociaciones Indígenas, registros de la Comisión de Desarrollo de Isla de Pascua. Este mecanismo de reconocimiento permite que el SERVEL identifique a los ciudadanos indígenas, pero adicionalmente la población puede acreditar su condición indígena mediante certificado que entrega CONADI (Servicio Electoral de Chile, 2021).

En la práctica la papeleta verde no siempre fue solicitada por los electores indígenas o bien los vocales de mesa no diferenciaban la pertenencia indígena del votante, por lo que solo era entregado el voto para Constituyente. Esta situación, esperable al tratarse del primer ejercicio político de inclusión indígena, también es un factor a considerar para justificar la baja participación (El Desconcierto, 2021). 
En total son 17 escaños reservados disponibles para la población indígena, siete de ellos disponibles para la población mapuche acorde a las regiones donde habita su población, dos para aymaras y uno para cada uno de los ocho pueblos restantes. Las elecciones, además, se efectuaron en una doble jornada: 15 y 16 de mayo de 2021, contando con una menor participación en comparación con el Plebiscito 2020. Fue la primera votación donde se incluye al padrón indígena y un voto específico para cada pueblo indígena y sus candidatos constituyentes

\section{Lógicas de ayllu en la institucionalidad pública}

La institucionalidad pública puede generar rechazo en algunos sectores indígenas (Albert, 2019). La presencia de conflictos internos y vínculos personales puede superar un apoyo irrefutable hacia candidatos indígenas, así como muchos candidatos pueden presentar historias de trayectorias hacia el poder de manera más solitaria (Bengoa, 2000).

A pesar de ello, la autodeterminación se presenta como un objetivo transversal para las comunidades, lo que a su vez puede ser ejercido desde diversas aristas (Pairican, 2016). Reconocer que la población indígena es sujeta de derecho con sistemas propios de gobierno, justicia, identidad, lengua, cultura y, además, uso y control de sus territorios, también presenta una encrucijada interna, donde el ayllu, visto como un sistema de gobierno ancestral de Qollasuyu, ya cumple con estas demandas. Es decir, la participación y reconocimiento en la institucionalidad pública presenta el desafío de ser capaz de trasladar los niveles de validación con el que ya cuentan los ayllus, otras formas de interpretar la organización o la democracia. Por ello resulta interesante conocer sobre formas "alternativas" de política que siguen operando con sus propias lógicas, por lo que permitir la participación en la institucionalidad pública resulta un acto reivindicativo, pero no nuevo (Tapia, 2008). Precisamente la confianza que pueden generar los ayllus, $\mathrm{u}$ otras formas similares de gobierno, es que aseguran automáticamente la autodeterminación, a diferencia de la institucionalidad pública, donde se busca explicarla, sumar adherentes y obtenerla.

La demanda por autonomía de los pueblos originarios, como manera de llevar a ejercicio la autodeterminación, es parte de un proceso de empoderamiento político y una reorganización del espacio político, como ciudadano indígena, que proyecta una 
construcción del mañana y forja una unidad utópica que permite re imaginar un nuevo tipo de mundo sin perder las particularidades identitarias. Elaborar de esta forma un horizonte de futuro que se aglutine en un nuevo contrato social, no solo descenderán los niveles de violencia política como instrumento, evitará la transformación de una demanda por derechos civiles en una lucha étnica racial (Pairican, 2016, p. 107).

Una expresión de autodeterminación para el mundo andino son los ayllus. La existencia de estas unidades territoriales traspasa la era precolonial y resiste como centro de la organización comunitaria. Para los aymaras, la percepción del ayllu cuenta con un importante componente reivindicativo y activista. Su presencia estructura la vida política de las comunidades, sustentado en cosmovisiones andinas, siempre en diálogo con otras organizaciones; donde cada integrante cumple roles acorde a edad y género, sin los cuestionamientos actuales que realizan las miradas occidentales. El ayllu también se sustenta en una dinámica complementaria (Bengoa, 2004), con el arriba y abajo o arajj saya y manqha saya.

En La Paz, Bolivia, en el año 1993 ocurre un hecho particular: diversas comunidades deciden volver a organizarse como ayllus bajo sus propias autoridades, jilaqatas y mallkus como un acto de autonomía, buscando derechos territoriales. Los procesos políticos y reivindicativos aymaras y/o andinos, hoy expresados bajo los márgenes de Bolivia, constituyen actos reivindicativos poco conocidos, pero que cuestionan y tensionan las ideas del imaginario boliviano moderno y desarrollado. Bolivia alberga a comunidades indígenas dueñas de voces propias, liderando estos postulados en Qollasuyu.

Es importante para la población los procesos de autoidentificación y resistencia. Choque y Mamani (2001) rescatan la memoria histórica andina para descubrir la existencia de aymaras y otras naciones indígenas. Los procesos históricos bolivianos son relatados bajo un colonialismo crudo, latifundista, donde nuevamente se intentan negar y silenciar todo lo indígena. Sin embargo, son los ayllus quienes se vuelven una dificultad en el avance de las ideas republicanas y modernas, aunque parezcan disueltos siguen operando desde lo simbólico y su resurgimiento materializa la lucha reivindicativa indígena. 
El ayllu es un modelo de organización social cuya vigencia abarca a casi todos los pueblos indígenas de la región andina: Colombia, Ecuador, Perú, Bolivia y Chile. Se constituyen en modelo porque es jatha, la "semilla" de donde germinó la civilización y las estructuras políticas andina como el Tawantinsuyu. El ayllu, que equivale también a una familia (ali), es hasta hoy la unidad con la que se conforma nuestro tejido de organización social y político. Es la más pequeña, pero importante, unidad, y también refleja nuestra organización estatal (Choque y Mamani, 2001, p. 207).

El ayllu visiona a la tierra como una propiedad colectiva, su origen es precolonial, pero al mismo tiempo logra fusionar la tradición ancestral y algunas ideas coloniales. El ayllu también puede ser interpretado como símbolo de la identidad étnica. Recuperar estos valores permite reafirmar y consolidar la identidad del ayllu. Desde afuera se vuelve una garantía de la defensa del territorio, así se vuelve a la reapropiación del hábitat indígena, ideas que nunca fueron abandonadas y se materializaron en las tensiones con empresas mineras y el Estado, donde este último parece no querer renunciar a su desintegración (Choque y Mamani, 2001).

El poder es representado por el mallku, que también puede ser un cóndor de los Andes. En tanto en los ayllus o markas existe el Kuntur Mallku o Mallku Kunturi quien personifica a una autoridad. Estas lógicas propias de los ayllus es volver al Pachakuti, con sus propios tiempos y espacios, que permite sus propias formas de autogobierno. Estos Mallku representan a una colectividad y su legitimidad se avala con sus valores e incluso en la vestimenta (Choque y Mamani, 2001). El objetivo principal del Mallku es gobernar desde lo colectivo y desde su propio territorio, además de todos los problemas referidos al ayllu. En tanto, el Jilaqata vela por conflictos personales, reemplazando al Mallku solo en su ausencia. Esta organización también cuenta con un alcalde, un reflejo del colonialismo; además de un Muyu que verifica la situación de las familias. Para Choque y Mamani (2001) hay una desestructuración permanente del ayllu, comenzar a revalorar esta forma de organización permite corroborar la situación colonial a la que se someten y precisamente justifica su reconstitución. La memoria reconstituye lo comunal y étnico de la unidad.

Lo doméstico, lo privado, es de gran relevancia en el ayllu y no es subvalorizado como sucede en occidente. El ayllu regula la producción 
agrícola, es decir, uno de los componentes del "vivir bien". El derecho a la gestión propia es avalado por tratados internacionales. Hoy, las comunidades andinas indígenas, y particularmente aymaras, entienden que cuentan con el apoyo y la razón para reposicionar al ayllu como eje central en lo político y lo doméstico. Una propuesta decolonial de relaciones interétnicas que cuestiona a sociedad actuales.

La reconstitución del ayllu, de lo propio, de la autodeterminación, ocurre a mediados de los años 80. Basadas en principios ideológicos-políticos se unen diversas propuestas para crear y consolidar un gobierno originario propio, creando lazos con otros pueblos y buscando revitalizar la organización del ayllu. Esto considera recuperar estructuras políticas ancestrales de complementariedad, donde hombres y mujeres participan y toman decisiones en cargos públicos (Gutiérrez, 2018). Walsh (como se citó en Gutiérrez, 2018) menciona que el género y el patriarcado son construcciones modernas que devienen en la idea de raza, como reflejo de la intromisión del colonialismo y sus propias formas de gobernanza y poder, donde la colonialidad limita el imaginario indígena. Cuándo la mujer vuelve a ser parte del ejercicio del poder se debe dar desde las dinámicas comunitarias del ayllu, no con miradas occidentales. Si bien el espacio privado también está dotado de poder, para occidente implica su reducción o se podría considerar como machista. Lo público y privado organizan las relaciones de poder. La autora también apunta al sistema educativo y militar como los promotores de instaurar el patriarcado, pues los saberes propios eran desvalorados ante los pensamientos de occidente.

El ejercicio político les enseña a sobreponerse frente a cualquier situación de violencia psicológica, y reconducir con valores éticos y de la manera más equilibrada posible, en la lógica propia de la complementariedad, mostrando su amplio potencial descolonizador hacia las nuevas generaciones (Gutiérrez, 2018, p.45-46).

El Estado no garantiza ciertos derechos y surge la dicotomía entre buscar nuevas formas autónomas de organización o buscar mayor incidencia política al interior de las instituciones. Al respecto, el autor boliviano Luis Tapia hace referencia al concepto de "Política Salvaje" (2008) como una forma de desarmar y criticar la forma social existente sin necesariamente ser un proyecto de orden social alternativo. Estas formas de intervención salvaje son los motores de los cambios sociales, ya sea porque preexisten o porque son disfuncionales para el sistema político. 
Una vez que la política se ha separado de las comunidades humanas bajo la forma estatal, que resulta de la estructuración de nuevas desigualdades en su seno, los individuos y las colectividades han buscado el reconocimiento de una nueva igualdad a través de esa forma general de la política, pues nada en la vida social tiende a adquirir el carácter de lo general sino a particularizarse. La fluidez de los movimientos salvajes que alude Tapia (2008) son reformas progresivas que contienen prácticas de resistencia y rechazo a las formas de dominación y desigualdad política existentes sin tener un significado por alguien en particular, una ideología o una coalición. Es decir, muchas propuestas desde el subsuelo son en sí mismas política salvaje. Los movimientos indígenas son un nuevo actor social que desafía a las instituciones y políticas públicas, ya que existe un debate al considerarlos parte de los nuevos movimientos sociales o como organizaciones descoloniales o como la consecuencia de una larga historia dentro de las lógicas de los movimientos sociales clásicos (Bengoa, 2000).

\section{Metodología}

\section{Objetivo}

Analizar la participación en las elecciones de constituyentes indígenas de las siguientes comunidades: aymaras, changos, collas, diaguitas, atacameños o lickanantay y quechuas; y la participación de sus habitantes para la elección de Constituyentes indígenas. Para ello se busca entregar un análisis de aproximación sociológica aplicado en las cifras que entrega el Servicio Electoral de Chile, SERVEL.

\section{Técnica de obtención de datos}

Desde el Servicio Electoral de Chile, SERVEL, se obtienen los datos duros de los pueblos indígenas de lo que hoy conocemos como Chile, pero vinculados con Qollasuyu, destacándose el número de electores inscritos, votos válidamente emitidos, votos nulos, votos en blanco, total de votos y el porcentaje total de participación. Estos datos se expresan en la Tabla $\mathrm{N}^{\mathrm{o}} 1$ "Cifras de participación de pueblos indígenas de Qollasuyu en las elecciones de Constituyentes Indígenas en Chile, año 2021”. 


\section{Tabla 1}

Cifras de participación de pueblos indígenas de Qollasuyu en las elecciones de Constituyentes Indígenas en Chile, año 2021

\begin{tabular}{|c|c|c|c|c|c|c|}
\hline 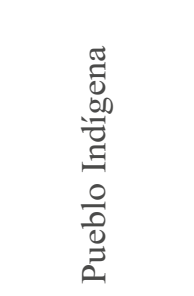 & 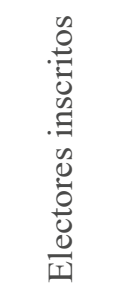 & 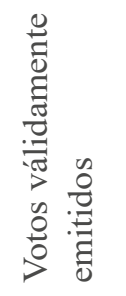 & 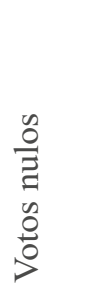 & $\begin{array}{l}0 \\
0 \\
\Xi \\
0 \\
0 \\
0 \\
0 \\
0 \\
0 \\
0 \\
0\end{array}$ & $\begin{array}{l}0 \\
0 \\
0 \\
0 \\
\frac{\pi}{0} \\
0\end{array}$ & 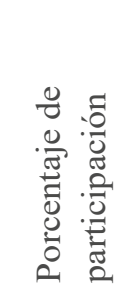 \\
\hline Aymaras & 75.743 & 19.241 & 305 & 634 & 20.180 & $26,64 \%$ \\
\hline Atacameños & 22.569 & 6.772 & 109 & 146 & 7.027 & $31,13 \%$ \\
\hline Changos & 1.951 & 910 & 28 & 21 & 959 & $49,15 \%$ \\
\hline Collas & 9.183 & 2.138 & 19 & 54 & 2.211 & $24,07 \%$ \\
\hline Diaguitas & 53.887 & 11.239 & 138 & 230 & 11.607 & $21,53 \%$ \\
\hline Quechuas & 7.661 & 2.076 & 55 & 53 & 2.184 & $28,50 \%$ \\
\hline
\end{tabular}

Tabla de creación propia a partir de datos de www.servelelecciones.cl

\section{Resultados y análisis}

\section{En relación a la mayor participación por pueblo indígena}

Al enfocarse en el territorio de Qollasuyu, como se enfatiza en el apartado de Introducción, solo se considerará a seis pueblos indígenas de los diez reconocidos a la fecha por el Estado de Chile. Como lo señala la Tabla No 1 , es el pueblo Chango el que cuenta con mayor participación en estas elecciones, con un $49.15 \%$, a pesar de contar con el menor número de electores inscritos. La presencia del mundo chango se extiende por la zona costera de las regiones de Antofagasta, Atacama, Coquimbo y Valparaíso; usualmente siendo abordados por los libros escolares de historia como un pueblo cuya principal característica era el uso de cuero de lobos marinos con diversos fines. Recordemos que el pueblo chango cuenta con un reciente 
reconocimiento por parte del Estado chileno, el cual se concretó el 23 de enero y se ratificó el 30 de abril del año 2019, siendo su aprobación definitiva el 8 de octubre del 2020 mediante la Ley $N^{\circ} 21.273$ que modifica la Ley Indígena $\mathrm{N}^{\circ} 19.253$ (Ministerio de Desarrollo Social y Familia, 2021).

En el año 2007 se presenta un primer proyecto de Ley de Reconocimiento, avalado por la gran cantidad de personas que ya se consideraban como changos. Su invisibilización, al igual que con diaguitas, se traduce en la interpretación como pueblos extintos, cuyos vestigios se remontan a artefactos arqueológicos. Su resistencia y existencia obedece a las transformaciones culturales e identitarias, además de la autoadscripción a la indigeneidad (Campos et al., 2019).

Varios años atrás, la presencia de quienes decían "ser changos" o "descendientes changos" generaba suspicacia; sin embargo, existían las condiciones para referirse a ellos como categoría histórica por su modo identitario de autodenominación que, al mismo tiempo, es una categoría identitaria que cuenta con un constante "llenado de contenido" que los hace prevalecer, con diversas formas para autoconsiderarse chango desde la memoria de antepasados hasta la multiplicidad de formas de crear su identidad (Mandel, 2008). Su visibilización y demandas van en sintonía con diversos grupos en la región que reivindican sus formas preexistentes de comprender el mundo y la obtención de derechos con enfoque indígena.

La particularidad del mundo chango puede ser relacionada con el territorio que habitan. Considerando la distinción geográfica de Qollasuyu, los Changos son un pueblo costero ligado a labores relacionadas con el mar, marcando una forma particular de construir su identidad y reconocer el territorio que habitan. Probablemente su cosmovisión se asienta en un espacio diferente al resto de los pueblos considerados en este artículo, más ligados a las visiones andinas. Por último, su fuerte participación en estas elecciones se puede interpretar como una respuesta a su reciente reconocimiento, volviéndolos un sector de la población indígena interesados en ejercer sus derechos y participar activamente en procesos nuevos para ellos, lo que lleva a suponer la existencia de una cohesión previa con diversos fines, siendo uno de sus primeros logros su propio reconocimiento. 


\section{En relación al pueblo con menor porcentaje de participación}

En el "Norte Chico", en las regiones de Atacama y Coquimbo, se encuentra asentada gran parte de la población diaguita. Relacionados también como las culturas Molle y Las Ánimas. Los diaguitas, que también habitan Argentina, fueron distinguidos de otras culturas por su cerámica que rescata los jarros patos. En la expansión de Tahuantinsuyu, al igual que con otras comunidades del norte, se logró asimilar ciertas características de los dominantes, justificando también los elementos en común del mundo andino. Sin embargo, su incorporación al incario también significó cambios culturales (Ministerio de Agricultura, 2014).

Las actuales voces diaguitas comienzan a realizar primeras acciones de visibilización y reconocimiento en el año 2002. Esta solicitud se concreta en el año 2006 bajo el gobierno de Michelle Bachelet mediante la Ley $\mathrm{N}^{\mathrm{o}}$ 20.117 donde son incorporados a la Ley Indígena; siendo las localidades de Copiapó, Huasco, Valle de Elqui, Limarí, entre otros, quienes albergan a la mayoría de las 45.314 personas que se reconocían como diaguitas en el Censo del 2012 (Ministerio de Agricultura, 2014). En la bibliografía diaguita, un hito clave para su reconocimiento fue la instalación del proyecto minero de Pascua Lama de la minera transnacional Barrick Gold. El proyecto buscaba extraer principalmente oro, plata y cobre, y abarcaba territorios de la Provincia de Huasco en Chile y de la Provincia de San Juan en Argentina, es decir, territorio ancestral diaguita. El proyecto fue cerrado definitivamente en el año 2020 por el Tribunal Ambiental de Antofagasta y se considera un hito relevante en el mundo indígena y su lucha por detener el avance del extractivismo.

La llegada del proyecto pone en jaque a la comunidad diaguita, la cual manifiesta su rechazo al proceso de participación ciudadana. Al contar con el reconocimiento indígena, a pesar que la instalación minera ya se encontraba en funcionamiento, pueden acogerse a diversos tratados internacionales y contar con el apoyo de medioambientalistas. La categoría de indígenas entrega nuevas condiciones de trato y de consulta que permiten aminorar el impacto extractivista, además de entregar continuidad al relato diaguita (Alcota, 2019).

En relación a la identidad diaguita, se configura su relación con el territorio como un anclaje con herencia a un lugar, donde un pasado común puede ser la migración forzada y asimilación cultural. Por ello resulta destacable 
la visión del "otro", pero desde la capacidad diaguita de comprender sus particularidades y desde allí construir un sentido de pertenencia. La acción colectiva que permite el reconocimiento diaguita permite construir una identidad y apego al lugar considerando, además, la interpelación de identidades, inscripción de la memoria y el bienestar cultural:

La interpelación de otro consiste en mostrar un posicionamiento en base a un relato respecto a la inscripción de la memoria, que entrega nutrientes para la adscripción y diferenciación grupal y lazo con el lugar. En esta interpelación se cuestiona el relato dominante, que ha construido la realidad establecida como normal y válida (Alcota, 2019, p. 178-179).

Para justificar la baja participación diaguita en estas elecciones se podrían barajar las hipótesis relacionadas con un debilitamiento reciente en la cohesión del grupo diaguita, entre otras causas, o bien por la no aprobación interna del proceso constituyente, cuestionado además por otros pueblos indígenas. Si bien la etnogénesis diaguita fue un hito importante en la lucha contra Pascua Lama, esta autoadscripción no se vio reflejada en esta ocasión. Sin embargo, la comunidad comprende la plenitud de derechos a los que acceden con el reconocimiento, principalmente ante amenazas externas como lo seguirá siendo el extractivismo, por lo que se destaca la resistencia diaguita expresada en ámbitos más allá de la elección de Constituyentes Indígenas.

\section{En relación a los electores inscritos y a los votos válidamente emitidos}

Claramente la población indígena que lidera la Tabla $\mathrm{N}^{\mathrm{o}} 1$ es la población aymara. Con 75.743 electores inscritos y 19.241 votos válidamente emitidos, se posiciona como la primera nación del norte con mayor densidad, lo que justifica que cuenten con dos escaños entre los constituyentes indígenas; sin embargo, no son el pueblo que cuenta con mayor porcentaje de participación. La población aymara, hoy situada en territorios de Chile, Argentina, Perú y Bolivia, cuenta también con una amplia experiencia en relación a sus propias formas de gobernanza y organización, como se presenta en el apartado cinco. Además, cuentan con una participación activa y reconocimiento en los países vecinos, lo que se traduce en movimientos sociales basados en 
el indigenismo que muestran formas contrahegemónicas de comprender la acción política de sus colectivos (Valer, 2011).

La Plurinacionalidad de Bolivia, según autores como Pairican (2016) y Rivera Cusicanqui (2014), se traduce en una nueva identidad indígena, xampurria o ch'ixi como menciona la autora, donde el desafío se relaciona con qué hacer con los colonialismos internos. Bolivia posee etnicidad estratégica, lo que permite mayor participación en institucionalidad pública. Hay una mejor distribución de riquezas que logra disminuir las cifras de pobreza, pero que, a juicio de Rivera Cusicanqui, se impide la emancipación de los orígenes, más bien se crean estrategias en base a la etnicidad. Por ello se sugiere una visión hegemónica universal más que particular, dando espacio a otras demandas locales y contando con mayores espacios de acción (Pairican, 2016).

En el Censo del 2002 (Condori, 2016), se menciona a la comunidad aymara como la segunda mayoría en cuanto a población indígena con 692.192 habitantes. Si bien sus demandas son compartidas por otros pueblos indígenas, en particular el término de "buen vivir o vivir bien" es una reivindicación más compleja. Se menciona que los estándares suelen basarse en la posesión de objetos materiales, donde se olvida el equilibro, el respeto y la reciprocidad. La escasa cantidad de aymaras que manejan la lengua o que habitan territorios ancestrales también incide en la disminución de autoridades como yatiris.

Rivera Cusicanqui (2018) crítica el modelo boliviano, donde se ornamenta la identificación étnica como forma compensatoria que impide ver a los sujetos ch'ixi o xampurrios que habitan estos territorios. Diversos movimientos sociales en Bolivia se han levantado en las últimas décadas como intento de contrarrestar la homogenización de lo indígena y otras disputas conceptuales. La autora menciona que el Estado convierte a estos movimientos en "mecanismos funcionales a la dominación estatal y capitalista" (p. 105). La identidad boliviana tiene conciencia de minoría y también puede ser racializada. Estas críticas, sumadas a movimientos de insurgencia étnica como el katarismo, cuestionan la Plurinacionalidad boliviana como una alternativa que solucione conflictos ancestrales de reconocimiento y opresión.

En Chile, a pesar de que existen otros intentos organizativos, muchos de ellos parecen disolverse tras la entrada en vigencia de la Ley Indígena y 
la CONADI. Los líderes son cooptados (Bengoa, 2000) como funcionarios públicos, mientras las ONG o representantes de la sociedad civil comienzan a vincularse con las organizaciones. La etnoburocracia aymara que surge es criticada por integrarse a lógicas de poder estatal y hegemónico, contribuyendo al debilitamiento del tejido social y perdiéndose un correlato territorial e incentivando disputas Ya en los años 90, con las consecuencias del extractivismo cada vez más evidentes, las agrupaciones indígenas se reagrupan, esta vez bajo discursos ligados a la autonomía y reconocimiento de su especificidad, pero principalmente por el rescate de sus propias formas de organización. A pesar de ello, se produce un quiebre en las organizaciones al no compartir el interés por preservar un correlato étnico o un discurso etnopolítico (Poblete, 2010). Eventualmente, la redacción de una Nueva Constitución podría aminorar las distancias entre agrupaciones y dirigentes, siendo un desafío replicar las lógicas de ayllu en la institucionalidad pública; sin embargo, al ser el primer ejercicio democrático indígena en Chile, los posibles acuerdos debiesen permitir acercarse a fines mayores o más complejos, acordes no solo a necesidades y demandas, sino también a tiempos y procesos que no siempre coinciden con lo occidental.

\section{En relación con otros pueblos indígenas fuera de Qollasuyu}

Wallmapu es el territorio indígena más extenso, considerando a Puelmapu, lo que hoy se considera como parte del territorio argentino. Es el pueblo con mayor presencia en el padrón electoral indígena, lo que permite que cuenten con siete escaños reservados. Hablamos de un total de 1.063.980 electores inscritos, siendo válidos la cantidad de votos de 217.884 (Servicio Electoral de Chile, 2021). Se presentaron 39 candidatos y candidatas acompañadas de otra persona acorde a la paridad de género. Es precisamente la participación mapuche la que genera mayor expectación en la Convención, incluso algunos medios de comunicación ya consideraban ganadora a la machi Francisca Linconao Huircapan. Su figura no solo nos habla de una importante autoridad mapuche con saberes ancestrales, sino también recuerda sobre la persecución política a la que estuvo expuesta. También es destacable la perspectiva con la que cuenta en relación al poner al servicio sus conocimientos y pensamientos en la Carta Magna, garantizando plurinacionalidad y el buen vivir como ejes centrales (Ñanculef, 2021). Estos vaticinios no fueron certeros, pero sí aproximados. El 4 de julio del 2021 
es electa como Presidenta de la Convención Constitucional Elisa Loncon, profesora mapuche, académica con una vasta trayectoria disciplinar, quien investiga sobre la lengua mapuzungun (El Mostrador, 2021). Este logro no solo es un acto simbólico de apoyo a las primeras naciones, sino que también habla de la incipiente presencia de mujeres indígenas en la institucionalidad pública (Ibacache-Corante, 2020). Su presencia, y la de todos los indígenas, contribuye a que puedan visualizar su propio futuro, donde la definición de plurinacionalidad dentro de la Constitución cobra importancia; además del reconocimiento de nuevos derechos expresados en nuevos sistemas (Figueroa Huencho, 2021).

\section{Conclusiones}

Para comprender la triada chango/diaguita/aymara destacada en el presente trabajo es necesario ahondar en las experiencias recientes de las comunidades, que logran unir o distanciar a su población acorde a la contingencia, pero sin disolver los lazos comunitarios que son la base de su identidad. Es decir, hablamos de una necesidad imperante de reconocimiento estatal ante la amenaza extractivista (diaguitas), la importancia del reconocimiento de una identidad preexistente y con rasgos fuera de lo andino que hablan de indigeneidad (changos) y participación más discreta en la institucionalidad pública ante la validación de otros sistemas de gobierno ancestrales y ante las experiencias políticas en otras naciones donde habitan hermanos indígenas (aymaras). Una posible vía para generar insumos a considerar podría ser retomar la idea de ayllu (Choque y Mamani, 2001) o considerar las experiencias de otras naciones de la región en materia de reconocimiento y participación (Naciones Unidas, 2021). No hay un estándar de organización, sino más bien depende de la fuerza del movimiento indígena al momento de negociar; pero, sin dudas, los escaños reservados permiten la representación de estos pueblos, además de sus propias lógicas de autogobierno (Fuentes y Sánchez, 2018). Denominar o pensar en Qollasuyu permite avanzar en la consolidación de un gran territorio indígena transnacional, idea que podría potenciar la participación en la institucionalidad chilena, siendo un acto más allá de una delimitación geográfica y arqueológica, permitiendo rememorar complejas estructuras sociopolíticas del ámbito andino (Rostworowski, 2019). 
En relación a la Convención Constituyente surgirán conflictos de interés $\mathrm{y}$, principalmente, algunas contradicciones con legislaciones y acuerdos internacionales donde el factor indígena es protagonista. Usualmente es el Convenio 169 de la OIT uno de los acuerdos más reconocidos al cual está suscrito Chile; sin embargo, la toma de decisiones en materia indígena tendrá mayor importancia al considerar la Declaración de los Derechos de los Pueblos Indígenas de la ONU. Considerar esta declaración como un estándar permite incorporar al debate los derechos humanos y el principio de la libre determinación (Naciones Unidas, 2021). Inicialmente lo indígena se abordaba desde la percepción de los derechos de las minorías, de los discriminados, pero los Pactos Internacionales hablan de una variedad de derechos, considerando incluso una mirada decolonial. A medida que estos Pactos se fueron actualizando, se denota que considerar dimensiones como el derecho a la cultura e idioma propios de las minorías étnicas no es suficiente, ni considerar estos derechos ni hablar de minorías (Políticas Públicas, 2021). En el año 2001 nace la Declaración ONU sobre los Derechos de los Pueblos Indígenas, la que presenta las bases para lograr un entendimiento común, tomando como referencia los derechos humanos, el contenido mínimo de los derechos de los indígenas: "Artículo 43: Los derechos reconocidos en la presente Declaración constituyen las normas mínimas para la supervivencia, la dignidad y el bienestar de los pueblos indígenas del mundo" (Naciones Unidas, 2007, p. 15).

Lo anterior también amerita un proceso de consulta indígena, en paralelo al proceso de redacción, sin esperar al Plebiscito de Salida para consultar por la aprobación de la ciudadanía (Políticas Públicas, 2021). La participación de constituyentes indígenas es acercarse a un trato de igualdad en la jurisdicción del Estado, como lo señala la Declaración de la ONU. Coexisten dos paradigmas que ameritan su identificación: una mirada decolonial que se basa en la libredeterminación y la mirada de los Derechos Humanos que considera la participación de los pueblos indígenas como un grupo inserto en una comunidad política (Becker y Alvez, 2020).

La redacción de una Nueva Constitución genera dudas en relación a la resolución de conflictos ancestrales. ¿Toda la población indígena en Chile aspira a la autodeterminación o ser un Estado Plurinacional? Hablar de plurinacionalidad sería un proyecto democrático radical en comparación con lo expresado con la Constitución nacida en dictadura. Independiente de los futuros resultados, en relación al contenido de la Constitución y su 
aprobación, las formas de resistencia, las formas alternativas de gobierno y la organización comunitaria seguirán prevaleciendo en Qollasuyu como en todo el territorio indígena.

Los avances y retrocesos en materia indígena y su participación en la institucionalidad pública siempre serán abordados por el Estado. Si los límites se relacionan con la soberanía y la autonomía por sobre los Derechos Humanos, sería incierto prever los escenarios políticos. Probablemente es el abordaje de las miradas mapuches lo que más conflictúa al Estado chileno, pues la relación entre ambas naciones suele estar tensionada (Figueroa Huencho, 2018). Paradójicamente, las falencias estatales en materias mapuches contribuyen a la adhesión internacional, basada en declaraciones como la de la ONU, por parte de la ciudadanía. Seguir entorpeciendo la libredeterminación no solo contribuye a una mala imagen del Estado chileno, sino a visibilizar diversas formas sistemáticas de ejercicios racistas y genocidas en pleno siglo XXI. 


\section{Referencias bibliográficas}

Albert, C. (2019, 7 de agosto). Los errores que liquidaron la consulta indígena: "Es una instrumentalización de la pobreza”. CIPER. Chile. https:/www.ciperchile.cl/2019/08/07/los-errores-que-liquidaron-laconsulta-indigena-es-una-instrumentalizacion-de-la-pobreza/

Alcota, P. (2019). Pueblo Diaguita, identidad étnica y apego al lugar: desde la memoria al bienestar cultural [tesis de doctorado, Universidad de Concepción]. Repositorio Institucional UDEC. http://repositorio.udec. $\mathrm{cl} / \mathrm{jspui} / \mathrm{handle} / 11594 / 445$

Becker A. y Alvez A. (2020). La consulta indígena en Chile: ¿Derecho de participación o de libre determinación? Estudios Sociales, 59 (2), 89-111. https://doi.org/10.14409/es.v59i2.8918

Bengoa, J. (2000). La Emergencia Indígena en América Latina. Fondo de Cultura Económica.

Bengoa, J. (comp.) (2004). La memoria olvidada. Historia de los Pueblos Indígenas de Chile. Compilación del Informe de la Comisión de Verdad Histórica y Nuevo Trato. Publicaciones del Bicentenario; Presidencia de la República. https://drive.google.com/file/d/1wi11ZGIZyI4SBjYS mmZzY6iXXq8du9Xe/view

Campos, L., Molina, R. y Mandel A. (2019). Antecedentes para el reconocimiento legal del Pueblo Chango. Serie Policy Papers, (6), 1-15. http://www.ciir.cl/ciir.cl/wp-content/uploads/2019/09/policypaper-UPP-n\%C2\%BA-6-2019-1-1.pdf

Centro de Estudios Interculturales e Indígenas CIIR. (2019, agosto). ELRI Estudio longitudinal de relaciones interculturales. Resultados Segunda Ola. http://www.elri.cl/wp-content/uploads/2019/08/Reporte-ELRIOla2-Agosto-2019.pdf

Condori, D. (2016). Perspectiva del pueblo aymara en el debate sobre una nueva Constitución. En D. Namuncura, J. Pinto, F. Pairican, E. Loncon, L. Cortés, Y. Provoste, D. Condori, P. Hucke, E. Licanqueo, C. Cuminao, M. Calfio, G. Huinao, L. Loncon. Nueva Constitución y Pueblos Indígenas. (pp.143-150). Pehuén Editores.

Choque, M. y Mamani, C. (2001). Reconstitución del ayllu y derechos de los pueblos indígenas: el movimiento indio en los Andes de 
Bolivia. The journal of Latin American Anthropology, (6), 202-224. https://doi.org/10.1525/jlca.2001.6.1.202

El Desconcierto. (2021, 16 de mayo). Elecciones 2021: Denuncian irregularidades con la entrega de votos a pueblos indigenas en varios puntos del país. El Desconcierto. https://www.eldesconcierto.cl/ nacional/2021/05/16/elecciones-2021-denuncian-irregularidades-conla-entrega-de-votos-a-pueblos-indigenas-en-varios-puntos-del-pais.html

El Mostrador. (2021, 17 de mayo). Participación Indígena: 22,81\% del padrón votó escaños reservados para pueblos originarios. El Mostrador. https:/www.elmostrador.cl/dia/2021/05/17/participacionindigena-2281-del-padron-voto-escanos-reservados-para-pueblosoriginarios/

El Mostrador. (2021, 4 de julio). Quién es Elisa Loncon, la profesora mapuche elegida presidenta de la Convención Constituyente de Chile. El Mostrador. https://www.elmostrador.cl/nuevaconstitucion/2021/07/04/quien-es-elisa-loncon-la-profesora-mapucheelegida-presidenta-de-la-convencion-constituyente-de-chile/

Figueroa Huencho, V. (2021, 20 de mayo). Lo conseguimos: una Convención Constituyente Plurinacional e Intercultural. CIPER. https://www.ciperchile.cl/2021/05/20/1o-conseguimos-unaconvencion-constituyente-plurinacional-e-intercultural/

Figueroa Huencho, V. (2018). Tierras y territorios indígenas: dimensiones complejas para las políticas públicas. El caso de la política "Acuerdo nacional por el desarrollo y la paz en la AraucaníaPlan Impulso Araucanía" en Chile. Serie Policy Papers, (2), 1-23. https:/www.ciir.cl/ciir_2019/wp-content/uploads/2018/12/policypaper-UPP-n\%C2\%BA2-2018.pdf

Fuentes, C. y Sánchez, M. (2018). Asientos reservados para pueblos indígenas, experiencia comparada. Serie Policy Papers, (1), 1-23. https:/www.ciir.cl/ciir_2019/wp-content/uploads/2018/07/policypaper-UPP-n\%C2\%BA1-2018-1.pdf

Gobierno de Chile. (2019). Acuerdo por la Paz Social y la Nueva Constitución. https://obtienearchivo.bcn.cl/obtienearchivo?id=docume ntos/10221.1/76280/1/Acuerdo_por_la_Paz.pdf 
González, J. y Valenzuela, E. (2017). Mapa de demandas etno-territoriales indígenas en Chile: mapuches - rapa nuis - diaguitas rebeldes, aymaras - atacameños consociativos. Revista Iberoamericana de Estudios Municipales, (16), 79-106. https://doi.org/10.32457/riem.vi16.336

Gutiérrez, Y. (2018). Mujeres aymaras y ejercicio político. Estudio de caso en la Marka Cantapa, municipio Laja, Bolivia [tesis de maestría, Universidad Andina Simón Bolívar]. Repositorio CAN. http://repositorio.uasb.edu.ec/handle/10644/6055

Henríquez, A. (2013). Participación indígena: desarrollo y alcances en torno a la participación ambiental. Revista Lut et Praxis, (19), 251-300. http://dx.doi.org/10.4067/S0718-00122013000200008

Ibacache-Corante, A. (2020). Pueblos Indígenas en vías de participación en la Institucionalidad Pública y Comunitaria: los casos de mujeres atacameñas (lickanantay) y aimaras. Revista Cuaderno de Trabajo Social, 15(1), 95-117.https://sitios.vtte.utem.cl/cuadernots/wp-content/ uploads/sites/10/2021/01/cuaderno-de-trabajo-social-n15-2020Ibacache.pdf

Mandel, A. (2008). Los Changos de Chañaral de Aceituno: dimensiones de una categoría histórica [tesis de licenciatura. Universidad Academia de Humanismo Cristiano]. Género, Historia, Ruralidad. https:/generohistoriaruralidad.cl/pdf/tesis/tesis\%20astrid\%20mandel.pdf

Ministerio de Agricultura. (2014). Diaguitas chilenos: serie introducción histórica y relatos de los Pueblos Originarios de Chile. https://www.fucoa.cl/publicaciones/pueblos_originarios/diaguitas.pdf

Ministerio de Desarrollo Social y Familia. (2020, 23 de diciembre). Ley 21.298 de 2020. Modifica la carta fundamental para reservar escaños a representantes de los pueblos indígenas en la convención constitucional y para resguardar y promover la participación de las personas con discapacidad en la elección de convencionales constituyentes. Biblioteca del Congreso Nacional de Chile. http://bcn.cl/2mwem

Ministerio de Desarrollo Social y Familia. (2021, 17 de octubre). Ley 21.273 de 2021. Modifica la Ley $N^{o} 19.253$ que establece normas sobre protección, fomento y desarrollo de los indígenas, y crea a la Corporación Nacional de Desarrollo Indígena, para reconocer al pueblo Chango como etnia indigena de Chile, entre otras materias. 
Diario Oficial n. ${ }^{\circ}$ 42.782.https://www.diarioconstitucional.cl/ wp-content/uploads/2020/10/Ley No21.273.pdf

Molina, R. (2013). Diaguitas: emergencia étnica y dialéctica de las relaciones y conflictos interculturales en el Huasco Alto. En J. Durston (Coord.), Pueblos Originarios y sociedad nacional en Chile: la interculturalidad en las prácticas sociales (pp. 115-127). Programa de las Naciones Unidas para el Desarrollo. https:/www.academia.edu/13821269/ pueblos_originarios_y_sociedad_nacional_en_chile

Naciones Unidas (2021). Pueblos Indigenas y Constitución. https://www. pueblosindigenasyconstitucion.cl/?fbclid=IwAR3fTOXeGtBnXJQUC xziG2zDEp0NKuV-7menuBiy15sH4Ggrya1FXlnv1Sk

Naciones Unidas (2007). Declaración de las Naciones Unidas sobre los Derechos de los Pueblos Indigenas. https://www.un.org/esa/socdev/ unpfii/documents/DRIPS_es.pdf

Nanculef, W. (2021, 4 de mayo). Machi Francisca Linconao, candidata constituyente: "Cuando yo esté ahí escribiendo la Constitución, nadie me va a parar". El Desconcierto. https://www.eldesconcierto. cl/reportajes/2021/05/04/machi-francisca-linconao-candidataconstituyente-cuando-yo-este-ahi-escribiendo-la-constitucion-nadieme-va-a-parar.html

Pairican, F. (2016). Resquebrajando la República homogénea: la lucha por derechos civiles indígenas. En D. Namuncura, J. Pinto, F. Pairican, E. Loncon, L. Cortés, Y. Provoste, D. Condori, P. Hucke, E. Licanqueo, C. Cuminao, M. Calfio, G. Huinao, L. Loncon. Nueva Constitución y Pueblos Indígenas. (pp.105-113). Pehuén Editores.

Poblete, D. (2010). Movimientos y organizaciones politicas y sociales del pueblo aymara: el caso de Arica-Parinacota y Tarapacá, Chile [tesis de doctorado,UniversidadComplutensedeMadrid]. RepositorioCONICYT. http://repositorio.conicyt.cl/handle/10533/180715?show=full

Políticas Públicas. [@ceppdi]. (2021, 29 de mayo).¿Cuál es el estándar internacional en materia de derecho internacional de Derechos de Pueblos Indígenas? Es un punto clave para los trabajos constituyentes de Chile 2021. Comencemos por afirmar: el estándar no es el Convenio 169 de la OIT, es la Declaración ONU [tuit]. Twitter https://twitter.com/ceppdi/status/1398843281799364612 
Quijano, A. (2013). Sobre la colonialidad del poder. Conferencia magistral impartida por Aníbal Quijano. Contextualizaciones Latinoamericanas, (8), 1-6. http://www.revistascientificas.udg.mx/ index.php/CL/article/view/2792

Rivera Cusicanqui, S. (2018). Un mundo chi xi es posible. Tinta Limón.

Rivera Cusicanqui, S. (2010). Ch'ixinakax utxiwa: una reflexión sobre prácticas y discursos descolonizadores. Tinta Limón.

Rostworoski, M. (2019). Historia del Tahunatinsuyu. Instituto de Estudios Peruanos.

Servicio Electoral de Chile (2021). Pueblos Indígenas en la Convención Constitucional. https://elecciones2021.servel.cl/ pueblos-indigenas-en-la-convencion-constitucional/

Soto, F., Brito, S., Klenner M., Ledesma, J. y Núñez, A. (2019). La Constitución en debate. Un texto pensado para profesores, estudiantes y organizaciones sociales. LOM Ediciones.

Tapia, L. (2008). Política salvaje. Muela del diablo editores.

Valer, P. (2011). Movimiento social e indigenismo político aymara, descentralización y proyecto de Estado Multinacional. Revista de Análisis y Crítica, (5), 1-5. https://argumentos-historico.iep.org. pe/articulos/movimiento-social-e-indigenismo-politico-aymaradescentralizacion-y-proyecto-de-estado-multinacional/ 